\title{
EDITORIAL
}

\section{Rugby setting the pace}

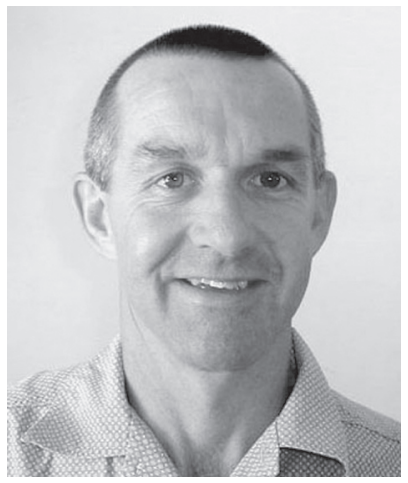

This is the last edition of the South African Journal of Sports Medicine for 2007. Four editions of the journal have been published in 2007, with 21 articles (original research, opinions and letters). Over $50 \%$ of these articles are unique to the South African context. It is becoming more difficult to publish good-quality research with a local interest in international journals so therefore it is logical that the 'local' journals assume the responsibility of publishing this work. The goal of the South African Journal of Sports Medicine is to encourage and increase this proportion of published articles while still maintaining a high standard. Sometimes researchers feel that high-quality research of a local interest is 'wasted' in a local journal because they do not get the credit for the paper that they would get from an international journal. We are cognizant of this and are in the process of getting the South African Journal of Sports Medicine ISI rated. This international rating is a difficult and lengthy process and involves a peer review of the journal over several years. We are confident we have met all the requirements and wait with keen anticipation for the outcome of the review which is currently underway. We should have feedback by the middle of 2008. Once the journal is ISI rated all published papers will be incorporated into the Pubmed database and will therefore get much more international exposure. The journal is currently on the government-accredited list of journals and this status will not be negatively affected if the journal gets ISI accreditation.

While we glow in the success of the Springboks at the Rugby World Cup it is appropriate to reflect on the contribution that the sports medicine support staff made to the victorious team. After reading Jake White's book (In Black and White) it is clear that the coach valued the input of his medical support team and acknowledged the role they had in the success of the team. The management of the health and fitness of professional rugby players in South Africa is world class, and rugby is the only sport which consistently implements a multidisciplinary approach in managing the players. A challenge for all of us is to utilise this vast database of experience and intellect, and transfer it to the other sports which are currently lagging behind. Fingers are crossed that we are not going to be exposed in the 2008 Olympics in Beijing. The support structures for rugby worked together for 4 years - at the time of writing the medical support team for the Olympics 6 months away has not yet been announced.
On another note, the journal is going to have to be stricter about publishing papers which do not have appropriate ethical clearance - this includes informed consent from subjects. This is a trend being adopted in journals all over the world. There is also some talk about the Department of Health playing a bigger role in granting permission for research to be done on children, particularly at schools. While it may be argued that this will tighten up the standard of research and reduce the risk of poor-quality studies, there is also concern that this will be another bureaucratic hurdle which researchers are required to clear. Anyone dealing with the Medicines Control Council from a research perspective will know that the bureaucracy is unwieldy - another body imposing the same level of bureaucracy will stifle many aspiring projects. Surely the various ethics committees around the country can fulfil the role of quality control?

\section{News}

The South African Sports Medicine Association (SASMA) and the South African Institute for Drug Free Sport have announced a partnership to combat doping in sport. The past president of SASMA, Dr Demitri Constantinou, said that 'SASMA is pledging its members to respect the rule of law in the fight against doping and to practise ethically in that respect; and further, in the optimal care of athletes and sports participants at all levels, using best practice knowledge and models. Athletes sanctioned for doping offences may have been incorrectly advised and guided by some health care practitioners, sometimes even deliberately, and these professionals should be held accountable'.

Dr Louis Holzthausen is the new president of SASMA. The staff of the journal wishes him all the very best for his term of office. The past president, Dr Demitri Constantinou, is congratulated and thanked for the tireless effort he has put into SAMA during his term of office.

\section{Mike Lambert}

Editor-in-Chief 